\title{
Porphyria cutanea tarda presenting as milia and blisters
}

\author{
Long Hoai Nguyen MD, Karima Khamisa MD
}

Cite as: CMAJ 2018 May 22;190:E623. doi: 10.1503/cmaj.180152

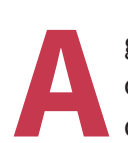

generally healthy 71-yearold woman was referred to dermatology for evaluation of a six-month history of large blisters on the dorsal surface of both hands, associated with mild pruritus and burning. When we examined the patient's hands, we observed multiple vesicles and milia, as well as open bullae larger than $5 \mathrm{~mm}$ (Figure 1A). Her only medications were iron supplements taken orally for "fatigue" over the past few months. She consumed two alcoholic beverages per week. A skin biopsy showed a wide band of perivascular immunoreactivity consistent with porphyria cutanea tarda. Urine porphyrin analysis was positive for elevated levels of uroporphyrins.

Porphyria cutanea tarda is an uncommon disease that most frequently occurs in men older than 40 years. ${ }^{1-3}$ It is caused by a deficiency in the enzyme uroporphyrinogen decarboxylase, which ultimately causes an elevation in uroporphyrinogens (highly photosensitive molecules that can cause damage to sun-exposed extremities). Porphyria cutanea tarda is precipitated by alcohol use, hemochromatosis (hereditary or acquired), hepatitis $C$ virus and HIV infection, exposure to estrogen, or smoking. ${ }^{3}$

Porphyria cutanea tarda most commonly presents as bullae, vesicles, increased skin fragility, scarring, altered pigmentation and hypertrichosis. ${ }^{1,2}$ However, milia can be observed in porphyria cutanea tarda (Figure 1). Milia are white, keratinous cysts that may develop spontaneously or as secondary lesions associated with the healing process of other cutaneous lesions, such as pemphigus vulgaris, epidermolysis bullosa, second-degree burns, bullous pemphigoid and bullous lichen planus., ${ }^{4,5}$

We advised our patient to stop taking iron supplements and consuming alcohol, and to wear sunscreen on her extremities. She was started on a course of monthly therapeutic phlebotomy to remove excessive iron. After three months, her ferritin declined to $432 \mu \mathrm{g} / \mathrm{L}$ (from $997 \mu \mathrm{g} / \mathrm{L}$ at diagnosis; normal range $11-307 \mu \mathrm{g} / \mathrm{L}$ ), with complete resolution of her blistering lesions. However, multiple milia persisted (Figure 1B) as the residual manifestation of porphyria cutanea tarda.

\section{References}

1. Handler NS, Handler MZ, Stephany MP, et al. Porphyria cutanea tarda: an intriguing genetic disease and marker. Int J Dermatol 2017;56:e106-17.

2. Ramanujam V-MS, Anderson KE. Porphyria diagnostics - Part 1: a brief overview of the porphyrias. Curr Protoc Hum Genet 2015;86:17.20.1-26.

3. Bissell DM, Anderson KE, Bonkovsky HL. Porphyria. N Engl J Med 2017;377:862-72.

4. Bolognia JL, Schaffer JV, Cerroni L. Dermatology. 4th ed. Philadelphia: Elsevier Saunders; 2018.

5. Habif TP. Clinical dermatology: a color guide to diagnosis and therapy. 6th ed. St. Louis (MO): Edinburgh; 2016.

Competing interests: Karima Khamisa sits on the advisory boards for Alexion Pharma Canada, Novartis and Amgen Canada, and has received speaker's fees from Alexion Canada, outside the current work. No other competing interests were declared.

This article has been peer reviewed.

The authors have obtained patient consent.

Affiliation: Faculty of Medicine, University of Ottawa, Ottawa, Ont.

Correspondence to: Karima Khamisa, kkhamisa@toh.ca

Clinical images are chosen because they are particularly intriguing, classic or dramatic. Submissions of clear, appropriately labelled highresolution images must be accompanied by a figure caption. A brief explanation (300 words maximum) of the educational importance of the images with minimal references is required. The patient's written consent for publication must be obtained before submission. 